\title{
High Level Physical Activity and Prevalence of Cardiovascular Disease Using the Korea National Health and Nutrition Examination Survey Data, 2007-2013
}

\author{
Kyounghoon Park, Byung-Joo Park \\ Department of Preventive Medicine, Seoul National University College of Medicine, Seoul, Korea
}

Objectives: The purpose of our study was to evaluate the association between the intensity of physical activity (PA) and prevalence of cardiovascular disease (CVD) using Korean representative data.

Methods: We analyzed 39804 participant data from the Korea National Health and Nutrition Examination Survey, 2007-2013. Exposure variable was three levels of PA (low, medium, and high) in a week, and outcome variable was prevalence of CVD based on patient self-recognition and doctor's diagnosis. Complex logistic regression analysis was performed to evaluate the relationship between level of PA and CVD adjusted by body mass index, hypertension, hypercholesterolemia, diabetes mellitus, stress recognition, household income, smoking, and current drinking. The indices of association w ere estimated as crude prevalence odds ratio (POR), adjusted POR, and their $95 \%$ confidence interval (CI). All statistical analyzes were performed using complex sample analysis procedure of the SPSS version 23.0.

Results: When all variables were adjusted, only high level PA in women showed a significant association with stroke (adjusted POR by patient's self-recognition, $0.57 ; 95 \% \mathrm{Cl}, 0.32$ to 0.99 , adjusted POR by doctor's diagnosis, $0.55 ; 95 \% \mathrm{Cl}, 0.34$ to 0.87 ) and CVD (adjusted POR by doctor's diagnosis, $0.68 ; 95 \% \mathrm{Cl}, 0.48$ to 0.96$)$.

Conclusions: High level PA in women has a significant reverse association with prevalence of stroke and CVD in Korea. Further study for elucidating the mechanism will be needed.

Key words: Exercise, Cardiovascular diseases, Public health, Health surveys, Republic of Korea

\section{INTRODUCTION}

Cardiovascular disease (CVD) is a disorder of the heart and blood vessels, which includes cerebrovascular disease, coronary/rheumatic heart disease, and other conditions [1]. CVD

Received: May 15, 2017 Accepted: August 31, 2017

Corresponding author: Byung-Joo Park, MD, PhD

103 Daehak-ro, Jongno-gu, Seoul 03080, Korea

Tel: +82-2-740-8325, Fax: +82-2-747-4830

E-mail: bjpark@snu.ac.kr

This is an Open Access article distributed under the terms of the Creative Commons Attribution Non-Commercial License (http://creativecommons.org/licenses/by$\mathrm{nc} / 4.0 /$ ) which permits unrestricted non-commercial use, distribution, and reproduction in any medium, provided the original work is properly cited. related to atherosclerosis, which is caused by the accumulation of a substance called atheromatous plaque on the walls of the arteries, results in narrowing or clogging of the blood vessels. Thus, blood flow is disturbed and supplies deficient oxygen to the tissue, resulting in CVD [2].

CVD was the highest cause of death in the world between 2000 and 2012 [3]. In 2012, more than 17.5 million people were killed by CVD. It was responsible for an estimated $31 \%$ of total global deaths [4]. In Korea, cancer was the first cause of death and CVD was the second in 2014 [5]. This means that national health management of CVD is very important.

CVD has been considered a multifactorial disease that is affected by not only personal factors but also socioeconomic 
factors. Therefore, to predict the risk of CVD, a number of risk factors should be considered together [6], such as Framingham risk score (FRS), age, diabetes mellitus (DM) status, smoking status, systolic blood pressure (SBP), total cholesterol (TC), and high-density lipoprotein cholesterol (HDL-C) [7]. Although physical activity (PA) is not included in the FRS, it was identified as a protective factor in the 1967 Framingham Heart Study [8].

In addition, other studies have shown that PA, including walking, is a protective factor for CVD [9-19]. However, most studies examined Western populations [9-15], and the association between level of PA and CVD was not consistent among studies.

We conducted an epidemiologic study to evaluate the association between intensity of PA and prevalence of CVD using Korean population representative data.

\section{METHODS}

\section{Study Population}

The study was based on data from the Korea National Health and Nutrition Examination Survey (KNHANES) 20072013. KNHANES uses a complex, stratified survey design that considers non-responses to provide representative data of the Korean population. It consists of three parts: health interview, health examination, and nutrition survey. The health interview and health examination are conducted by trained medical staff and interviewers. A week after these two surveys, dietitians conduct the nutrition survey at the participant's home. The health and nutritional status of Koreans can be analyzed using this data. It is also possible to measure changes in the prevalence of chronic diseases and disease risk factors and to reflect those changes in national health policies [20].

The number of total participants in KNHANES 2007-2013 was 58 423. We first excluded 14791 people aged under 20 years old. Participants without information on walking/moderate PA ( $n=3799)$ were excluded. Finally, we excluded participants who lacked information on prevalence of CVD $(n=29)$. As a result, the final study population was 39804 (Figure 1).

\section{Study Variables}

Information on gender, age (categorized into 7 groups: 20$29,30-39,40-49,50-59,60-69,70-79$, and $\geq 80$ ), current drinking (those who drank more than once a month during the past year and those who had not), smoking (more than 100 cigarettes smoked during their lifetime and current smoker status), PA status, high stress recognition (those usually feeling

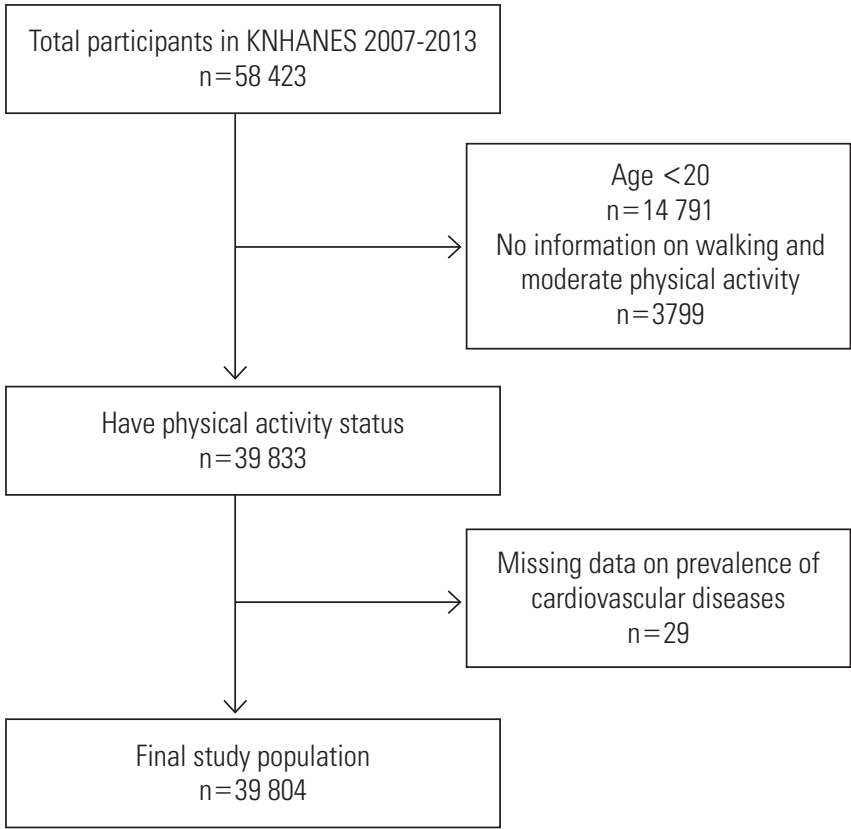

Figure 1. Flow of this study through data management in Korea National Health and Nutrition Examination Survey (KNHANES) 2007-2013.

considerable stress), and prevalence of CVD were obtained by self-administered questionnaire. Prevalence of hypertension (HTN), hypercholesterolemia (HC), and DM were determined by considering blood test results, the prescription of medication, and doctor's diagnosis. Current drinking, smoking, stress recognition, $\mathrm{HTN}, \mathrm{HC}$, and DM prevalence were calculated by the same methods used by the Korean Ministry of Health and Welfare [21]. Body mass index (BMI) was calculated from body weight and height $\left(\mathrm{kg} / \mathrm{m}^{2}\right)$, and was then categorized into 3 groups ( $<18.5,18.5-25.0$, and $\geq 25.0$ ). Household incomes for the survey year were divided into 4 groups: highest, intermittent high, intermittent low, and lowest.

PA status was obtained through the following questions: "During the last 7 days, on how many days did you walk for at least 10 minutes at a time? (This includes at work and school, walking to travel from place to place, and walking that you have done for exercise.)"“'During the last 7 days, on how many days did you do moderate PAs that take moderate physical effort or make you breathe somewhat harder than normal? Do not include walking. Think only about those PAs that you did for at least 10 minutes at a time (moderate PAs: job-related activities and sports such as carrying light loads or slow swimming, doubles tennis, volleyball, badminton, table tennis)" [22]. The KNHANES questions about walking and moderate PA 
are the same, except for the phrase "at least 10 minutes at a time," regarding moderate $\mathrm{PA}$, which has been missing from the KNHANES questionnaire since 2010. We performed a separate analysis of the prevalence of CVD, as determined by patient self-recognition and doctor's diagnosis. Self-recognition and doctor's diagnosis were both reported by self-administered questionnaire. "Self-recognition" was answered if the participant identified the disease by themselves, and "doctor's diagnosis" was answered if they received their disease diagnosis from a doctor.

\section{Association Between Intensity of Physical Activity} and Prevalence of Cardiovascular Disease

We categorized intensity of PA at three levels, which consisted of low, middle, and high. High level was defined as moderate PA for more than $30 \mathrm{~min} / \mathrm{d}$ for 5 days a week, regardless of the degree of walking. Middle level was defined as walking for more than $30 \mathrm{~min} / \mathrm{d}$ for 5 days a week but did not belong to high intensity level. Low level was defined as walking at any duration below the middle level. Walking for more than 30 $\mathrm{min} / \mathrm{d}$ for 5 days a week was a measure of walking rate announced by the Korea National Statistical Office [23]. Moderate PA for more than $30 \mathrm{~min} / \mathrm{d}$ for 5 days a week was the minimum intensity recommended by the American Heart Association (AHA) [24].

The prevalence of stroke, myocardial infarction (MI), angina, and CVD were analyzed separately. We analyzed the association between the three levels of PA and the prevalence of CVD. Multivariate logistic regression analysis was performed to adjust by potential confounding factors, including gender, age, BMI, HTN, HC, DM, smoking, stress recognition, household income, and current drinking. All risk factors that had at least the possibility of "contributing" to CVD, as indicated by the AHA, were selected [25].

Stratification analysis was conducted to show the effects of gender. The differences in social behavior and sex hormones attributed to gender significantly impacted the prevalence of CVD $[26,27]$.

\section{Statistical Analysis}

A chi-square test was used to compare categories of variables, and prevalence odds ratios (POR) were calculated using logistic regression. When the $p$-value was less than 0.05 , it was regarded statistically significant. All statistical analyses were performed using complex sample analysis procedures of the
SPSS version 23 (IBM Corp., Armonk, NY, USA).

\section{RESULTS}

\section{General Characteristics}

Study participants were divided into 3 groups, according to their level of PA. The low level group was 21993 people, the middle level was 13 591, and the high level was 4220. Men were more likely to have a high PA level than women. Age, $\mathrm{BMI}$, and stress recognition differed in the 3 groups and did not show any tendencies. HTN and HC had a lower prevalence with higher levels of PA. DM showed the same trend but was not statistically significant $(p=0.29)$. Groups with less smoking and alcohol consumption and higher household income had higher levels of PA (Table 1).

\section{Association Between Intensity of Physical Activity and Prevalence of Cardiovascular Disease}

We estimated the POR and their $95 \%$ confidence intervals (CI) between intensity of PA and prevalence of CVD. The prevalence was stratified by patient self-recognition and doctor's diagnosis of CVD. All prevalence of MI was not associated with $\mathrm{PA}$, regardless of adjustment. When regarding prevalence of disease by patient self-recognition, CVD was related to high level PA (adjusted POR, $0.76 ; 95 \% \mathrm{Cl}, 0.58$ to 0.99 ). When considering the prevalence of disease by doctor's diagnosis, $\mathrm{Ml}$ (adjusted POR, 0.56; 95\% Cl, 0.32 to 0.98) and CVD (adjusted POR, $0.75 ; 95 \% \mathrm{Cl}, 0.59$ to 0.95 ) had significant associations with high level PA in multivariate analysis (Table 2).

We conducted stratification analysis by gender. In men, the prevalence of stroke, $\mathrm{MI}$, angina, and CVD was unrelated to the intensity of PA after adjustment. Additionally, there was no trend of the POR according to the intensity of PA (Table 3). In women, however, the prevalence of stroke by patient self-recognition (adjusted POR, $0.57 ; 95 \% \mathrm{Cl}, 0.32$ to 0.99 ) was associated with high level PA. Higher level PA showed a lower risk of stroke ( $p$ trend $=0.05$ ). High intensity PA was related to stroke (adjusted POR, 0.55; $95 \% \mathrm{Cl}, 0.34$ to 0.87 ) and CVD (adjusted POR, $0.68 ; 95 \% \mathrm{Cl}, 0.48$ to 0.96 ) by doctor's diagnosis (Table 4).

\section{DISCUSSION}

We conducted the analysis under the assumption that the patient's own illness condition and the condition of the illness 
Table 1. Characteristics of participants by physical activity category in Korea National Health and Nutrition Examination Survey 2007-2013

\begin{tabular}{|c|c|c|c|c|}
\hline General factor & $\begin{array}{l}\text { Low level } \\
\text { ( } n=21 \text { 993) }\end{array}$ & $\begin{array}{c}\text { Middle level } \\
(n=13 \text { 591) }\end{array}$ & $\begin{array}{c}\text { High level } \\
(n=4220)\end{array}$ & $p$-value \\
\hline Weighted $\mathrm{n}$ & 20162089 & 12549120 & 3698153 & $<0.05$ \\
\hline \multicolumn{5}{|l|}{ Gender } \\
\hline Men & 47.1 & 51.7 & 53.8 & \\
\hline Age (y) & & & & $<0.05$ \\
\hline $20-29$ & 15.8 & 23.1 & 19.5 & \\
\hline $30-39$ & 22.4 & 20.5 & 20.4 & \\
\hline $40-49$ & 24.0 & 19.5 & 22.4 & \\
\hline $50-59$ & 18.5 & 16.6 & 20.6 & \\
\hline $60-69$ & 10.4 & 11.4 & 10.8 & \\
\hline $70-79$ & 7.4 & 7.7 & 5.8 & \\
\hline$\geq 80$ & 1.5 & 1.0 & 0.7 & \\
\hline Body mass index $\left(\mathrm{kg} / \mathrm{m}^{2}\right)$ & & & & $<0.05$ \\
\hline$<18.5$ & 4.9 & 4.9 & 3.5 & \\
\hline $18.5-25.0$ & 62.4 & 64.2 & 62.8 & \\
\hline$\geq 25.0$ & 32.7 & 30.9 & 33.7 & \\
\hline Hypertension & & & & $<0.05$ \\
\hline Yes & 25.1 & 24.0 & 22.5 & \\
\hline No & 74.9 & 76.0 & 77.5 & \\
\hline Hypercholesterolemia & & & & $<0.05$ \\
\hline Yes & 12.2 & 11.2 & 9.9 & \\
\hline No & 87.8 & 88.8 & 90.1 & \\
\hline Diabetes mellitus & & & & 0.29 \\
\hline Yes & 8.8 & 8.4 & 8.1 & \\
\hline No & 91.2 & 91.6 & 91.9 & \\
\hline Smoking & & & & $<0.05$ \\
\hline Current smoker & 25.4 & 26.2 & 28.0 & \\
\hline Past smoker & 19.5 & 20.4 & 20.9 & \\
\hline Non-smoker & 55.1 & 53.4 & 51.2 & \\
\hline Stress recognition & & & & $<0.05$ \\
\hline High & 28.6 & 26.2 & 28.1 & \\
\hline Low & 71.4 & 73.8 & 71.9 & \\
\hline Household income & & & & 0.04 \\
\hline Highest & 28.9 & 28.5 & 31.1 & \\
\hline Intermittent high & 28.9 & 28.6 & 28.6 & \\
\hline Intermittent low & 26.1 & 26.3 & 26.3 & \\
\hline Lowest & 16.1 & 16.5 & 14.0 & \\
\hline Current drinking & & & & $<0.05$ \\
\hline$\geq 1 / \mathrm{mo}$ & 56.9 & 59.4 & 60.9 & \\
\hline$<1 /$ mo & 43.1 & 40.6 & 39.1 & \\
\hline Physical activity limitation & & & & $<0.05$ \\
\hline Yes & 11.8 & 10.0 & 10.4 & \\
\hline No & 88.2 & 90.0 & 89.6 & \\
\hline
\end{tabular}

Values are presented as weighted \%.

High level: doing moderate activity (job-related activities and sports like carrying light loads or slow swimming, double tennis, volleyball, badminton, table tennis. Do not include walking) more than 5 days in a week and 30 minutes at a time; Middle level: doing walking more than 5 days in a week, 30 minutes at a time, and did not belong to high level; Low level: something that doesn't middle level physical activity. diagnosed by the doctor could lead to differing CVD prevalence data. However, we did not find a difference in prevalence in the results.

Our results indicate that the benefit of PA reducing CVD applies only to women. Kim et al. [28] cohort study demonstrated that any moderate PA above 150, $75 \mathrm{~min} / \mathrm{wk}$ of vigorous intensity, or $\geq 150 \mathrm{~min} / \mathrm{wk}$ of moderate or vigorous PA did not reduce CVD mortality in 12538 middle-aged (40 to 59) Korean men (adjusted hazard ratio [aHR], $0.87 ; 95 \% \mathrm{Cl}, 0.60$ to 1.26 ). Park et al. [29] also reported light, moderate or vigorous PA for at least $90 \mathrm{~min} / \mathrm{wk}$ were not associated with CVD mortality when PA's 1st and 3rd tertile were compared in a hospitalbased cohort study of 18775 Korean men, carried out between 1995 and 2003 (aHR, 1.01; 95\% Cl, 0.35 to 2.95). Other studies also reported women had more benefits from PA than men [18]. In our study, the proportion of high level PA among women was lower than in men. High level PA may influence CVD more greatly in women than in men.

Only moderate PA for more than $30 \mathrm{~min} / \mathrm{d}$ for 5 days a week (roughly estimated at least 11-15 metabolic equivalent task [MET]-hr/wk) is associated with lower prevalence of CVD. Cheng et al. [16] demonstrated that at least $4 \mathrm{hr} / \mathrm{wk}$ of mild and moderate exercise, which were roughly estimated at 12 $16 \mathrm{MET}-\mathrm{hr} / \mathrm{wk}$, could not reduce risk of acute Ml in a hospitalbased case-control study conducted in China between 1999 and 2003 (adjusted odds ratio [aOR], 0.96; 95\% Cl, 0.84 to 1.10), but the risk was significantly reduced by strenuous exercise (aOR, $0.75 ; 95 \% \mathrm{Cl}, 0.60$ to 0.93 ) such as running/jogging, football, and vigorous swimming. Wang et al. [17] conducted a prospective cohort study with 61477 Chinese men and reported more than 13.9 MET-hr/wk exercise could reduce risk of CVD (aHR, 0.76; $95 \% \mathrm{Cl}, 0.64$ to 0.90 ) compared with no regular exercise. Less than 13.9 MET-hr/wk could not reduce risk of CVD (aHR, $0.82 ; 95 \% \mathrm{Cl}, 0.68$ to 1.00$)$. Soares-Miranda et al. [14] reported that walking and exercise decreased risk of CVD regardless of the intensity and time based on 4207 US men and women in a prospective cohort study. Yates et al. [15] used data from 40 European (50.9\%) and American (35.0\%) countries to suggest that a 2000 step per day increment in ambulatory activity, roughly equal to $20 \mathrm{~min} / \mathrm{d}$ or $1.0-1.5 \mathrm{MET}-\mathrm{hr} / \mathrm{wk}$, decreased the risk of CVD by $10 \%$. In Asian countries, more high intensity PA could indicate more health benefit for CVD than in Western countries.

In recent systematic review studies [30-32], it has been maintained that PA was a preventive factor for CVD. Wahid et al. [30] 
Table 2. POR by different level of physical activity in KNHANES 2007-2013

\begin{tabular}{|c|c|c|c|c|c|c|c|}
\hline & \multicolumn{3}{|c|}{ Crude POR (95\% CI) } & \multicolumn{4}{|c|}{ Adjusted POR $(95 \% \mathrm{CI})^{1}$} \\
\hline & $\begin{array}{l}\text { Low level } \\
(n=21 \text { 993) }\end{array}$ & $\begin{array}{c}\text { Middle level } \\
(n=13 \text { 591) }\end{array}$ & $\begin{array}{c}\text { High level } \\
(n=4220)\end{array}$ & $\begin{array}{l}\text { Low level } \\
(n=21 \text { 993) }\end{array}$ & $\begin{array}{l}\text { Middle level } \\
(n=13591)\end{array}$ & $\begin{array}{c}\text { High level } \\
(n=4220)\end{array}$ & $\begin{array}{c}p \text { trend of } \\
\text { adjusted POR }\end{array}$ \\
\hline Weighted n & 20162089 & 12549120 & 3698153 & 20162089 & 12549120 & 3698153 & \\
\hline \multicolumn{8}{|c|}{$\begin{array}{l}\text { Prevalence of disease } \\
\text { Patient self-recognition }\end{array}$} \\
\hline Stroke & 1.00 (reference) & $1.01(0.82,1.25)$ & $0.66(0.46,0.97)$ & 1.00 (reference) & $1.08(0.84,1.39)$ & $0.71(0.47,1.06)$ & 0.42 \\
\hline $\mathrm{Ml}$ & 1.00 (reference) & $1.03(0.77,1.38)$ & $0.54(0.30,0.96)$ & 1.00 (reference) & $0.92(0.66,1.30)$ & $0.62(0.34,1.13)$ & 0.16 \\
\hline Angina & 1.00 (reference) & $0.85(0.68,1.06)$ & $0.79(0.55,1.12)$ & 1.00 (reference) & $0.91(0.71,1.16)$ & $0.94(0.64,1.36)$ & 0.52 \\
\hline CVD & 1.00 (reference) & $0.95(0.82,1.11)$ & $0.70(0.55,0.90)$ & 1.00 (reference) & $0.98(0.83,1.17)$ & $0.76(0.58,0.99)$ & 0.18 \\
\hline \multicolumn{8}{|c|}{ Doctor's diagnosis } \\
\hline Stroke & 1.00 (reference) & $1.00(0.84,1.18)$ & $0.65(0.47,0.90)$ & 1.00 (reference) & $1.10(0.90,1.35)$ & $0.72(0.50,1.04)$ & 0.41 \\
\hline $\mathrm{Ml}$ & 1.00 (reference) & $1.10(0.84,1.44)$ & $0.55(0.33,0.94)$ & 1.00 (reference) & $1.02(0.75,1.40)$ & $0.56(0.32,0.98)$ & 0.16 \\
\hline Angina & 1.00 (reference) & $0.90(0.73,1.10)$ & $0.83(0.61,1.13)$ & 1.00 (reference) & $0.96(0.77,1.19)$ & $0.90(0.64,1.25)$ & 0.50 \\
\hline CVD & 1.00 (reference) & $0.99(0.87,1.13)$ & $0.71(0.57,0.88)$ & 1.00 (reference) & $1.03(0.88,1.20)$ & $0.75(0.59,0.95)$ & 0.14 \\
\hline
\end{tabular}

High level: doing moderate activity (Job-related activities and sports like carrying light loads or slow swimming, double tennis, volleyball, badminton, table tennis. Do not include walking) more than 5 days in a week and 30 minutes at a time; Middle level: doing walking more than 5 days in a week, 30 minutes at a time, and did not belong to high level; Low level: something that doesn't middle level physical activity.

POR, prevalence odds ratio; KNHANES, Korea National Health and Nutrition Examination Survey; Cl, confidence interval; MI, myocardial infarction; CVD, cardiovascular disease.

${ }^{1}$ Adjusted: age, body mass index, hypertension, hypercholesterolemia, diabetes mellitus, smoking, stress recognition, household income, current drinking and physical activity limitation.

Table 3. Men's POR by different level of physical activity in KNHANES 2007-2013

\begin{tabular}{|c|c|c|c|c|c|c|c|}
\hline & \multicolumn{7}{|c|}{ Men's physical activity in KNHANES 2007-2013 } \\
\hline & \multicolumn{3}{|c|}{ Crude POR (95\% CI) } & \multicolumn{4}{|c|}{ Adjusted POR $(95 \% \mathrm{CI})^{1}$} \\
\hline & $\begin{array}{l}\text { Low level } \\
(n=8813)\end{array}$ & $\begin{array}{l}\text { Middle level } \\
(n=6141)\end{array}$ & $\begin{array}{c}\text { High level } \\
(n=1896)\end{array}$ & $\begin{array}{l}\text { Low level } \\
(\mathrm{n}=8813)\end{array}$ & $\begin{array}{l}\text { Middle level } \\
\quad(n=6141)\end{array}$ & $\begin{array}{l}\text { High level } \\
(n=1896)\end{array}$ & $\begin{array}{c}p \text { trend of } \\
\text { adjusted POR }\end{array}$ \\
\hline Weighted $n$ & 9489829 & 6487908 & 1988797 & 9489829 & 6487908 & 1988797 & \\
\hline \multicolumn{8}{|c|}{$\begin{array}{l}\text { Prevalence of disease } \\
\text { Patient self-recognition }\end{array}$} \\
\hline Stroke & 1.00 (reference) & $1.16(0.87,1.54)$ & $0.73(0.43,1.23)$ & 1.00 (reference) & $1.22(0.87,1.72)$ & $0.79(0.45,1.37)$ & 0.93 \\
\hline Ml & 1.00 (reference) & $1.06(0.73,1.53)$ & $0.57(0.29,1.12)$ & 1.00 (reference) & $0.93(0.61,1.41)$ & $0.66(0.32,1.34)$ & 0.31 \\
\hline Angina & 1.00 (reference) & $0.91(0.65,1.28)$ & $0.79(0.46,1.36)$ & 1.00 (reference) & $0.88(0.62,1.25)$ & $0.86(0.48,1.53)$ & 0.46 \\
\hline CVD & 1.00 (reference) & $1.05(0.86,1.28)$ & $0.72(0.52,1.01)$ & 1.00 (reference) & $1.02(0.81,1.29)$ & $0.78(0.54,1.13)$ & 0.40 \\
\hline \multicolumn{8}{|c|}{ Doctor's diagnosis } \\
\hline Stroke & 1.00 (reference) & $1.12(0.89,1.40)$ & $0.71(0.44,1.14)$ & 1.00 (reference) & $1.14(0.87,1.50)$ & $0.82(0.49,1.37)$ & 0.93 \\
\hline $\mathrm{Ml}$ & 1.00 (reference) & $1.17(0.83,1.65)$ & $0.49(0.25,0.96)$ & 1.00 (reference) & $1.04(0.70,1.53)$ & $0.55(0.27,1.12)$ & 0.29 \\
\hline Angina & 1.00 (reference) & $0.99(0.73,1.34)$ & $0.95(0.61,1.47)$ & 1.00 (reference) & $0.94(0.68,1.28)$ & $0.88(0.54,1.45)$ & 0.55 \\
\hline CVD & 1.00 (reference) & $1.10(0.92,1.31)$ & $0.74(0.55,1.00)$ & 1.00 (reference) & $1.05(0.86,1.29)$ & $0.77(0.55,1.09)$ & 0.41 \\
\hline
\end{tabular}

High level: doing moderate activity (Job-related activities and sports like carrying light loads or slow swimming, double tennis, volleyball, badminton, table tennis. Do not include walking) more than 5 days in a week and 30 minutes at a time; Middle level: doing walking more than 5 days in a week, 30 minutes at a time, and did not belong to high level; Low level: something that doesn't middle level physical activity.

POR, prevalence odds ratio; KNHANES, Korea National Health and Nutrition Examination Survey; Cl, confidence interval; MI, myocardial infarction; CVD, cardiovascular disease.

'Adjusted: age, body mass index, hypertension, hypercholesterolemia, diabetes mellitus, smoking, stress recognition, household income, current drinking and physical activity limitation.

reported moderate PA was related with a lower risk of CVD mortality (relative risk [RR], $0.77 ; 95 \% \mathrm{Cl}, 0.71$ to 0.84 ) according to combined results of 36 studies. Li and Siegrist [31] conducted systematic review of prospective cohort studies and re- ported high leisure time PA reduced risk of CVD comparing to low level leisure activity in men ( $\mathrm{RR}, 0.76 ; 95 \% \mathrm{Cl}, 0.70$ to 0.82 ) and women (RR, $0.73 ; 95 \% \mathrm{Cl}, 0.68$ to 0.78$)$. After analyzing nearly 900000 participants, Nocon et al. [32] showed that PA 
Table 4. Women's POR by different level of physical activity in KNHANES 2007-2013

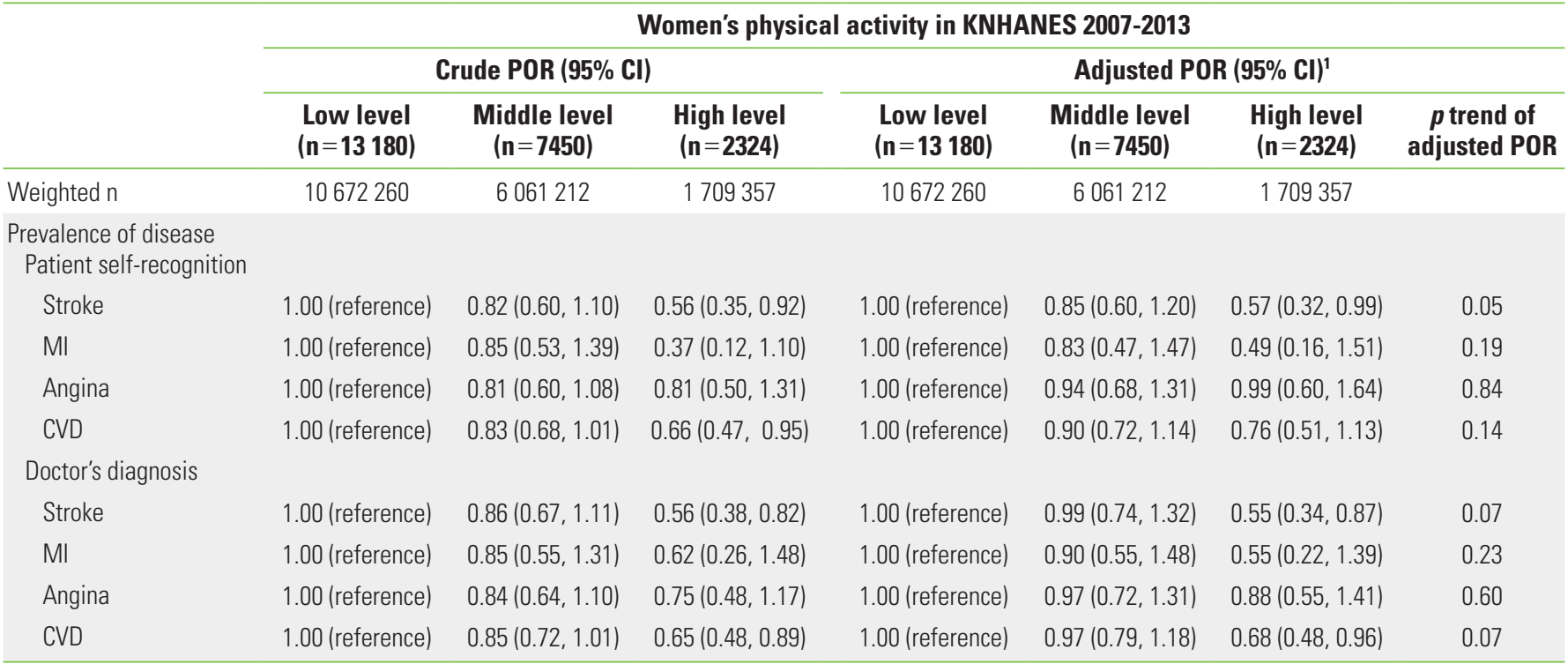

High level: doing moderate activity (Job-related activities and sports like carrying light loads or slow swimming, double tennis, volleyball, badminton, table tennis. Do not include walking) more than 5 days in a week and 30 minutes at a time; Middle level: doing walking more than 5 days in a week, 30 minutes at a time, and did not belong to high level; Low level: something that doesn't middle level physical activity.

POR, prevalence odds ratio; KNHANES, Korea National Health and Nutrition Examination Survey; Cl, confidence interval; MI, myocardial infarction; CVD, cardiovascular disease.

${ }^{1}$ Adjusted: age, body mass index, hypertension, hypercholesterolemia, diabetes mellitus, smoking, stress recognition, household income, current drinking and physical activity limitation.

reduced CVD mortality ( $\mathrm{RR}, 0.65 ; 95 \% \mathrm{Cl}, 0.60$ to 0.70$)$, and the effect of PA was greater for women than for men. However, it was difficult to determine the numerical cut-off values of the preventive effect of PA for CVD because the standards of PA, study design, measurements, and the study population were different among the studies.

PA could improve the body's abilities by enhancing muscular function and strength. It facilitates the transport and utilization of oxygen through the blood vessels. PA also enhances the vessels' dilation capacity when stressed by exercise or hormones. It also enables oxygen movement throughout the body. PA has physiological benefits and reduce risk factors of CVD. It could reduce body weight, low-density lipoprotein cholesterol, and TC, and increase HDL-C and insulin sensitivity [33]. Gender differences in the relationship between PA and CVD could be explained by differences in genes, hormones, and adaptive responses to PA, among others. However, due to the heterogeneity of studies and the diversity of mechanisms that cause CVD, the cause of this difference is not yet clearly explained [34].

KNHANES data is representative of the general population of Korea. Therefore, our analysis reveals the effects of gender and PA levels on CVD in Koreans. In addition, we combined data from years 2007 to 2013 , so it is suitable for analyzing low prevalence diseases, such as CVD. However, our study also has the following limitations. First, this study is a cross-sectional descriptive study. Although we describe the relationship between PA level and prevalence of CVD, it is difficult to prove that they have a causal relationship. However, it is widely known that PA is a protective factor for CVD. Second, questions about PA, prevalence of CVD, and others about health status may not collect objective information. Most estimations of our variables are carried out by self-administered questionnaire or face-to-face interview, which always implies the possibility of recall bias. In a previous study about KNHANES [35], there was a concordance between the self-administered questionnaire and the actual measurement of HTN, DM, and HC. The kappa values of HTN, DM, and HC were $0.72,0.82$, and 0.48 . The authors described the results as similar to studies in Europe and US. They also mentioned that the sensitivity needs to be increased. Third, we conducted the study to examine only 3 diseases of CVD: angina, $\mathrm{Ml}$, and stroke. Although these 3 diseases account for a large portion of CVD, they do not include all diseases of CVD.

We analyzed the association between the intensity of PA and the prevalence of CVD. In the future, further research is 
needed to reveal how the intensity of PA can prevent the risk of CVD in Korea, including considering additional variables such as health behavior and using objective PA measurement tools and better study design, such as a prospective cohort study or translational research.

\section{CONFLICT OF INTEREST}

The authors have no conflicts of interest associated with the material in this paper.

\section{ORCID}

Kyounghoon Park http://orcid.org/0000-0001-5800-917X

Byung-Joo Park http://orcid.org/0000-0003-4630-4942

\section{REFERENCES}

1. World Health Organization. Cardiovascular diseases [cited 2017 Jan 23]. Available from: http://www.who.int/cardiovascular_diseases/en/.

2. American Heart Association. What is cardiovascular disease? [cited 2017 Jan 10]. Available from: http://www.heart.org/ HEARTORG/Caregiver/Resources/WhatisCardiovascularDisease/What-is-Cardiovascular-Disease_UCM_301852_Article. jsp\#.WIWSYfmLSUI.

3. World Health Organization. The top 10 causes of death [cited 2016 Jun 1]. Available from: http://www.who.int/mediacentre/factsheets/fs310/en/.

4. World Health Organization. Cardiovascular diseases (CVDs)fact sheet [cited 2017 Jan 23]. Available from: http://www. who.int/mediacentre/factsheets/fs317/en/.

5. Statistics Korea. Mortality rate by cause of death [cited 2016 Jun 1]. Available from: http://index.go.kr/potal/main/EachDtlPageDetail.do?idx_cd=1012.

6. Ahn KA, Yun JE, Cho ER, Nam CM, Jang Y, Jee SH. Framingham equation model overestimates risk of ischemic heart disease in Korean men and women. Korean J Epidemiol 2006;28(2): 162-170 (Korean).

7. D'Agostino RB Sr, Vasan RS, Pencina MJ, Wolf PA, Cobain M, Massaro JM, et al. General cardiovascular risk profile for use in primary care: the Framingham Heart Study. Circulation 2008;117(6):743-753.

8. Hajar R. Framingham contribution to cardiovascular disease. Heart Views 2016;17(2):78-81.
9. Fitzgerald JD, Johnson L, Hire DG, Ambrosius WT, Anton SD, Dodson JA, et al. Association of objectively measured physical activity with cardiovascular risk in mobility-limited older adults. J Am Heart Assoc 2015;4(2):e001288.

10. Andersson C, Lyass A, Larson MG, Spartano NL, Vita JA, Benjamin EJ, et al. Physical activity measured by accelerometry and its associations with cardiac structure and vascular function in young and middle-aged adults. J Am Heart Assoc 2015;4(3): e001528.

11. García-Ortiz L, Recio-Rodríguez Jl, Schmidt-Trucksäss A, Puigdomenech-Puig E, Martínez-Vizcaíno V, Fernández-Alonso C, et al. Relationship between objectively measured physical activity and cardiovascular aging in the general population--the EVIDENT trial. Atherosclerosis 2014;233(2):434-440.

12. Setayeshgar S, Whiting SJ, Vatanparast H. Prevalence of 10year risk of cardiovascular diseases and associated risks in canadian adults: the contribution of cardiometabolic risk assessment introduction. Int J Hypertens 2013;2013:276564.

13. Soares TS, Piovesan CH, Gustavo Ada S, Macagnan FE, Bodanese LC, Feoli AM. Alimentary habits, physical activity, and Framingham global risk score in metabolic syndrome. Arq Bras Cardiol 2014;102(4):374-382.

14. Soares-Miranda L, Siscovick DS, Psaty BM, Longstreth WT Jr, Mozaffarian D. Physical activity and risk of coronary heart disease and stroke in older adults: the cardiovascular health study. Circulation 2016;133(2):147-155.

15. Yates T, Haffner SM, Schulte PJ, Thomas L, Huffman KM, Bales $\mathrm{CW}$, et al. Association between change in daily ambulatory activity and cardiovascular events in people with impaired glucose tolerance (NAVIGATOR trial): a cohort analysis. Lancet 2014;383(9922):1059-1066.

16. Cheng X, Li W, Guo J, Wang Y, Gu H, Teo K, et al. Physical activity levels, sport activities, and risk of acute myocardial infarction: results of the INTERHEART study in China. Angiology 2014; 65(2):113-121.

17. Wang N, Zhang X, Xiang YB, Li H, Yang G, Gao J, et al. Associations of Tai Chi, walking, and jogging with mortality in Chinese men. Am J Epidemiol 2013;178(5):791-796.

18. Hu G, Tuomilehto J, Borodulin K, Jousilahti P. The joint associations of occupational, commuting, and leisure-time physical activity, and the Framingham risk score on the 10-year risk of coronary heart disease. Eur Heart J 2007;28(4):492-498.

19. Folsom AR, Arnett DK, Hutchinson RG, Liao F, Clegg LX, Cooper LS. Physical activity and incidence of coronary heart disease in middle-aged women and men. Med Sci Sports Exerc 
1997;29(7):901-909.

20. Kweon S, Kim Y, Jang MJ, Kim Y, Kim K, Choi S, et al. Data resource profile: the Korea National Health and Nutrition Examination Survey (KNHANES). Int J Epidemiol 2014;43(1):69-77.

21. Korean Statistical Information Service. Statistical database [cited 2017 Jan 5]. Available from: http://kosis.kr/eng/statisticsList/statisticsList_01List.jsp?vwcd=MT_ETITLE\&parentld=D.

22. Kim WS. Comparison of physical activity questions in the Korea National Health and Nutrition Examination Surveys. Korean J Health Educ Promot 2012;29(3):23-34 (Korean).

23. Statistics Korea. Walking practice rate [cited 2016 Jun 4]. Available from: http://www.index.go.kr/potal/stts/idxMain/selectPoSttsldxSearch.do?idx_cd=2931\&stts_cd=293102 (Korean).

24. American Heart Association. Moderate to vigorous: what is your level of intensity? [cited $2017 \mathrm{Jul}$ 17]. Available from: http://www.heart.org/HEARTORG/HealthyLiving/PhysicalActivity/FitnessBasics/Moderate-to-Vigorous---What-is-yourlevel-of-intensity_UCM_463775_Article.jsp\#.WW1jxoTyiUk.

25. American Heart Association. Understand your risks to prevent a heart attack [cited 2017 Jul 17]. Available from: http://www. heart.org/HEARTORG/Conditions/HeartAttack/UnderstandYourRiskstoPreventaHeartAttack/Understand-Your-Risks-toPrevent-a-Heart-Attack_UCM_002040_Article.jsp\#.WW1pw4TyiUk.

26. Merz AA, Cheng S. Sex differences in cardiovascular ageing. Heart 2016;102(11):825-831.

27. Mosca L, Barrett-Connor E, Wenger NK. Sex/gender differences in cardiovascular disease prevention: what a difference a decade makes. Circulation 2011;124(19):2145-2154.
28. Kim JY, Ko YJ, Rhee CW, Park BJ, Kim DH, Bae JM, et al. Cardiovascular health metrics and all-cause and cardiovascular disease mortality among middle-aged men in Korea: the Seoul male cohort study. J Prev Med Public Health 2013;46(6):319328.

29. Park MS, Chung SY, Chang Y, Kim K. Physical activity and physical fitness as predictors of all-cause mortality in Korean men. J Korean Med Sci 2009;24(1):13-19.

30. Wahid A, Manek N, Nichols M, Kelly P, Foster C, Webster P, et al. Quantifying the association between physical activity and cardiovascular disease and diabetes: a systematic review and meta-analysis. J Am Heart Assoc 2016;5(9):e002495.

31. Li J, Siegrist J. Physical activity and risk of cardiovascular disease--a meta-analysis of prospective cohort studies. Int J Environ Res Public Health 2012;9(2):391-407.

32. Nocon M, Hiemann T, Müller-Riemenschneider F, Thalau F, Roll $S$, Willich SN. Association of physical activity with all-cause and cardiovascular mortality: a systematic review and metaanalysis. Eur J Cardiovasc Prev Rehabil 2008;15(3):239-246.

33. Myers J. Cardiology patient pages. Exercise and cardiovascular health. Circulation 2003;107(1):e2-e5.

34. Parker BA, Kalasky MJ, Proctor DN. Evidence for sex differences in cardiovascular aging and adaptive responses to physical activity. Eur J Appl Physiol 2010;110(2):235-246.

35. Chun H, Kim IH, Min KD. Accuracy of self-reported hypertension, diabetes, and hypercholesterolemia: analysis of a representative sample of Korean older adults. Osong Public Health Res Perspect 2016;7(2):108-115. 